\title{
CULTURAL DIFFERENCES IN \\ PARADOXICAL TENSIONS IN STRATEGY EPISODES
}

\begin{abstract}
In this conceptual paper, we ask: How does the larger cultural context influence the way that groups of managers deal with paradoxical tensions in strategy episodes? We focus on three sources of tension in the conduct and design of strategy episodes - inclusion, formality and coordination/communication. We argue that in each case, cultural influences affect the extent to which these facets of strategy episodes are dealt with using a paradox lens or not. Specifically, in Western cultural contexts, managers tend to have a lower proclivity for adopting a paradoxical frame resulting in a separation of tensions in strategy episodes; by contrast, managers in Eastern cultural contexts such as China more readily adopt a paradoxical frame, and embracing tensions in strategy episodes. We suggest that, over time, nonparadoxical thinking likely promotes inter-episode plurality and planned emergence, while paradoxical thinking tends to foster intra-episode plurality and emergent planning. We contribute to a deeper understanding of strategy episodes as culturally embedded practices.
\end{abstract}

Keywords: strategy episode; paradox; culture; East-West differences; China 


\section{CULTURAL DIFFERENCES IN \\ PARADOXICAL TENSIONS IN STRATEGY EPISODES}

Strategy-as-practice (SAP) scholars have drawn attention to strategy episodes typically a "sequence of events structured in terms of a beginning and an ending" (Hendry and Seidl, 2003, 180) such as away days and workshops - in which managers take time out of the everyday as part of the strategy making process. Hendry and Seidl's (2003) conceptualization suggests that strategy episodes inherently entail tensions around inclusion (whom to include and exclude), level of formality (high or low), and role in communicating and coordinating strategy (promoting stability or change). The prevalence of these choices (i.e. tensions) for managers designing and running strategy episodes has been seen in subsequent survey work (Healey, Hodgkinson, Whittington and Johnson, 2015; Hodgkinson, Whittington, Johnson and Schwarz, 2006), while qualitative studies have hinted that unless these tensions are managed adeptly, strategy episodes can fail (Hodgkinson and Wright, 2002; Jarzabkowski and Seidl, 2008; Johnson, Prashantham, Floyd and Bourque, 2010; Kryger, 2018; MacIntosh, MacLean and Seidl, 2010).

However, despite the burgeoning interest in SAP, little is known about the influence of culture on how these tensions in strategy episodes are addressed by managers. This is somewhat surprising given that an early emphasis in the underpinnings of SAP research was on cultural influence (Whittington, 1993). Yet, strategy episodes are not yet well understood as culturally embedded practices (Vaara and Lamberg, 2016) in terms of how larger contexts, such as the "wider cultures in which [strategy practices] are set" (Whittington, 2006, 615), influence the ways in which managers develop strategy. Pettigrew, Woodman and Cameron $(2001,702)$ noted several years ago that "in a culturally diverse and globally competitive world, scholars can only sit in discomfort in their own corners of the world pretending their patterns of change are the world's patterns of change". In a similar vein, Vaara and Whittington (2012, 
313) have suggested that "as the balance of the world economy changes, it is also important to examine the nature of strategy as a field in societies where the large managerially-controlled corporation has never been dominant, for example, China..." But the SAP domain is conspicuously silent on the issue of how strategy-making episodes may be influenced by culture. The time seems ripe for SAP scholars to emulate the growing interest within the broader domain of management research in "the contextual differences between the East and the West $^{1} \ldots$ and how they are manifest in contemporary management practices" (Barkema, Chen, George, Luo and Tsui, 2015, 460).

In seeking to address this lacuna, we draw upon a valuable research strand within the emergent body of work on paradox that sheds light on how culture affects managers' approach to tensions. Important work on culture and paradox has highlighted different proclivities to adopt a paradoxical frame between the West and East (Keller and Lewis, 2016; Keller, Loewenstein and Yan, 2017; Li, 2016). As Keller et al. (2017, 541) have noted, "Traditional western philosophy emphasizes separating paradoxical elements, whereas traditional eastern philosophy emphasizes integrating paradoxical elements". This is consistent with Li (1998, 2012, 2016) who has highlighted the importance of Yin Yang thinking in shaping Eastern attitudes to paradox: "While Americans tend to avoid paradoxes by separating opposites under the auspices of Aristotelian logic...the Chinese tend to seek for paradoxes by integrating opposites in accordance with Taoist logic" (Li, 1998, 839). Strategy-making episodes constitute a valuable setting in which to explore this contextual difference.

In this conceptual paper, our research question is: How does the larger cultural context influence the way that groups of managers deal with paradoxical tensions in strategy episodes? We focus on three sources of tension in the conduct and design of strategy episodes - inclusion,

\footnotetext{
${ }^{1}$ We recognize that the East-West distinction is a rather stark one, and that many contemporary organizations have culturally heterogeneous teams. However, akin to Weberian ideal types to facilitate systematic comparisons of a phenomenon, adopting such contrasting characterizations can be useful at an early stage of exploring cultural differences in a given research domain.
} 
formality and coordination/communication. We argue that in each case, cultural influences affect the extent to which these facets of strategy episodes are dealt with using a paradox lens. Specifically, we posit that Western managers have a lower proclivity for adopting a paradoxical frame resulting in a separation of tensions in strategy episodes; by contrast, Easterners more readily adopt a paradoxical frame, consistent with Yin Yang thinking, and integrate conflicting elements of strategy episodes. An important insight we provide is that, over time, paradoxical thinking tends to foster intra-episode plurality while non-paradoxical thinking likely promotes inter-episode plurality. More broadly, these practices support emergent planning and planned emergence, respectively.

Our core insight relates to how cultural influences shape distinct approaches to dealing with paradoxical tensions in strategy episodes. We thus contribute to SAP research by highlighting plausible distinctions in how managers do strategy in paradox-embracing and paradox-resisting cultural contexts, thereby responding to calls for deepening our understanding of strategy practices as culturally embedded events (Vaara and Lamberg, 2016; Vaara and Whittington, 2012). Also, we shed light on how contrasting strategy episode practices may support distinct strategy-making approaches - planned emergence in the West (Grant, 2003) and emergent planning in the East - and speculate that these approaches may have different strengths, such as strategic coherence and implementation speed, respectively. Beyond our core SAP audience, our ideas hold relevance to the paradox literature by offering a basis for digging further into strategy practices, in building upon emergent research interest at the intersection between paradox, culture and strategy (e.g. Keller and Chen, 2017a). Also, our work provides paradox scholars with potentially useful insight into organizational tensions, such as that between control and flexibility, through better understanding responses to tensions involved in the design and conduct of practices such as strategy episodes. 


\section{BACKGROUND}

\section{Paradoxical Tensions in Strategy-Making Episodes}

Embodied in SAP research is a growing recognition of strategy as something that people do (Burgelman, Floyd, Laamanen, Mantere, Vaara and Whittington, 2018; Whittington and Cailluet, 2008; Whittington, Yakis-Douglas, Ahn and Cailluet, 2017). Within this research stream, scholars have drawn attention to "the routines and norms of strategy work" (Whittington, 2007, 1579), with a distinct focus being on strategy practices such as designing and conducting strategy episodes (Hendry and Seidl, 2003). Strategy development is an episodic process (Wolf and Floyd, 2017). Strategy episodes fulfill the role of temporarily suspending the "normal constraints" of the everyday to allow communication and deliberation about strategy amongst organizational members (Hendry and Seidl, 2003). Several studies focus on strategy workshops (Healey et al., 2015; Hodgkinson and Wright, 2002; Jarzabkowski and Seidl, 2008; Johnson et al., 2010; MacIntosh et al., 2010) which refers to "the practice of taking time out from day-to-day routines to deliberate on the longer-term direction of an organization” (Hodgkinson et al., 2006, 479).

Hendry and Seidl's (2003) seminal work alludes to three interrelated paradoxical tensions in the design and conduct of strategy episodes concerning participation (who), purpose (why) and performativity (how). The participation tension relates to inclusiveness, an issue that has recently been highlighted in work on open strategy (Hautz, Seidl and Whittington, 2017). Some organizations seek to involve internal and external stakeholders by selectively involving them in strategy episodes, reflecting a tension around who to include and who to exclude since more inclusivity could enhance the diversity of the dialogue but impede strategic coherence. Moreover, the question of "who" cannot be addressed in isolation of the episode's purpose ("why") - that is, whether the focus is on change or stability (Jarzabkowski and Seidl, 2008). For instance, in some cases, it might be important to gain buy-in from external 
stakeholders, especially when significant changes are being planned, but there is also a tension in that too much change can result in unhealthy instability (Sewchurran, Dekker and McDonogh, 2018). Furthermore, the choices around an episode's purpose and participants will likely influence its performativity aspects, which were brought to the fore in Johnson et al.'s (2010) conceptualization of strategy episodes as ritual. Participants' conduct within a strategy episode manifest in more or less scripted (or formal) ways that may enable greater creativity but inhibit rigor (or the other way round), as well as reinforce the insider-outsider and stabilitychange tensions.

What are the sources of these tensions? In general terms, tensions arise from organizations' material conditions embedded in complex human systems, which are "inherently paradoxical since they are defined by boundaries between self and other, individuality and collaboration, and ingroup and outgroup (Smith and Lewis, 2011, 385). Seidl and colleagues note that while any organization contains irremovable paradoxes (Rasche and Seidl, 2018), strategy episodes offer a mechanism for suspending routine structures as a basis for reflecting upon (and potentially changing) those structures (Hendry and Seidl, 2003). The ontological compatibility of practice and paradox perspectives (Lê and Bednarek, 2017), seen in recent SAP work on how managers suppress or oppose tensions (Dameron and Torset, 2014; Jarzabkowski, Lê and Van de Ven, 2013; Jarzabkowski and Lê, 2017), indicates that organizational paradoxes often manifest in everyday practices.

Hodgkinson et al.'s $(2006,480)$ empirical analyses support the prevalence of tensions in strategy episodes as arising from the inherent nature of organizations and managers' competing strategic demands. They note that the three tension-related characteristics of strategy episodes that we focus on relate to "three broad issues in strategic management practice: first, the question of how strategies develop in both formal strategic planning practices widely seen as in decline and the more informal strategy-making processes; second, the new 
roles that formal strategy-making may now be developing, including softer ones such as communications and coordination; and third, who is actually included in these important parts of strategy development, given apparent shifts towards flatter organisational forms." Healy et al.'s (2015) subsequent work depicts these as choices pertaining to the design and conduct of strategy episodes, and underlines the view that obtaining successful outcomes from strategy episodes such as workshops is challenging, in part, because of paradoxical tensions stemming from choices that managers must make about the design and conduct of strategy episodes (Hodgkinson and Wright, 2002; Johnson et al., 2010). In the paragraphs that follow we expand on each of these three tensions, and later use them as the primary focus of our theory-building effort in terms of explicating how these tensions are addressed differentially in contrasting cultural settings.

Participation tension: Inclusion. In relation to inclusion, Hendry and Seidl (2003, 186) argue that strategy episodes entail bracketing in and bracketing out, which means that "what participants are to take part" - that is, who are included and, therefore, excluded - is an important choice in a strategy episode. Hodgkinson et al. $(2006,486)$ observe that while organizations are cognizant of "the importance of incorporating a wider range of stakeholder groups in the strategy-making process", in reality, individuals other than the top managers are often "marginalised because of power and status issues" (ibid., 487). This characteristic is further developed in a follow-up study by Healey et al. (2015) referring to this as "stakeholder involvement and participation", noting that "involving stakeholders other than top management (e.g. middle managers) in strategizing creates a collective sense of ownership, fairness and commitment ...whereas their omission can cause alienation and conflict." The implication is that there is likely to be a perceived contrast between "insiders" and "outsiders" in terms of who is included and who isn't. To illustrate, in a strategy episode described by Hodgkinson and Wright (2002), a core group of direct reports to the CEO were the primary participants 
(high level of exclusivity); by contrast, the facilitators and even some participants believed that broadening out the composition of the group would have made it more inclusive and effective but the CEO declined.

Given that various organizational members and different stakeholders influence strategy work, distinctions between their values and interests might cause conflicting tensions (Johnson et al., 2010; MacIntosh et al., 2010). Internal and external stakeholders often "have access to different information about the organization and apply different values and goals in interpreting this information." (Dutton, Dukerich and Harquail, 1994, 249). To illustrate, Ginzel, Kramera, and Sutton (1993) describe an organization where the attempts at imageenhancement caused a greater problem due to the differences in perception between organizational members and external stakeholders. Therefore, considering the differences between insiders and outsiders to an organization, the question of who should be included in an episode might involve conflicting tensions.

Thus a key tension in strategy-making episodes relates to "insiders versus outsiders". The prospect of being included in an episode such as a strategy workshop increases the likelihood that a participant feels a sense of belongingness vis-à-vis the organization (Healey et al., 2015; Hodgkinson et al., 2006; Johnson et al., 2010).

Performativity tension: Formality. As for formality, Hendry and Seidl $(2003,176)$ noted the prevalence of episodes "ranging from the informal and unofficial...to the formally scheduled", and thus vary in degree of disruption to the structures and routines of the organization; the less formal they are, the more open participants are to a variety of behaviors whereas the more, formal they are, the more scripted is the behavior. Hodgkinson et al. (2006, 489) suggest that the "spatial removal from the day-to-day operations" of strategy episodes has the effect of "underlining the sense that "strategy is different" which warrants designing an episode formally as a strategy-related event. A subsequent study by Johnson et al. (2010) takes 
the formality idea further. Drawing upon anthropology, they use the metaphor of the "liturgy" used in a ritual (e.g. a wedding ceremony) to characterize the extent of formality in strategy episodes which may entail carefully followed procedures such as going through presentations and conducting structured discussions using a strategy framework, in some cases led by external facilitators. An illustration that contrasts relatively more and less formal parts of a strategy episode is provided by Bourque and Johnson (2008, 553-555). They describe a formal "discussion of strategy" during the day which "consisted of competitor analysis and competence analysis" as well as "separate breakout groups to discuss the culture of their organization using a framework". But, by contrast, they also report participants getting together in "the more informal setting of the bar" where they could communicate freely. Such settings also would help participants avoid "talking shop".

Furthermore, strategy work represents a complex activity that involves simultaneously considering a number of elements at the same time, often "compounded with time pressures, market uncertainty and constant distractions and internal tensions" (Eppler and Platts, 2009, 42-43). Therefore, with respect to formality, it is important to decide what elements deserve primary attention for discussion at a specific workshop, which in turn influences the episode's format. Considering organizational members' differences in perspectives, some problems can be considered as more or less relevant to strategy work, and what must be handled more formally as opposed more informally. To illustrate this tension, Lüsher and Lewis $(2008,231)$ describe a situation in which "executives called for managers to build effective teams while ensuring productivity. One manager, in response, felt that he must address conflict within one of his teams, but he was concerned that such a [formal] discussion would become emotional, time consuming, and inefficient".

Thus a key tension in strategy-making episodes relates to whether the episode is "formal versus informal". The level of formality in a strategy episode affects actors' 
performative behaviors during a strategy episode; greater formality may induce analytical performative behaviors whereas greater informality potentially fosters affective bonds (Bourque and Johnson, 2008; Johnson et al., 2010).

Purpose tension: Coordination/Communication. Hendry and Seidl $(2003,177)$ note that in some cases, organization communication and coordination stemming from strategy episodes "provide stability and direction", while in others they are "very largely concerned with change". Thus central to an operation in an organization is whether strategy episodes are used to reproduce the status quo or induce change. Echoing this, Hodgkinson et al. $(2006,489)$ aver that in some cases, coordination/communication could result in surfacing "key issues that may well have been identified elsewhere in the organization" warranting new directions, while in other cases strategy episodes end up being "primarily forums for the socialising of [existing] strategy". Primarily, this aspect relates to the purpose of the episode. Consistent with Hendry and Seidl (2003), Johnson et al. (2010, 1597) make the distinction between episodes that promote change or stability. This contrast is illustrated by an organization they describe which conducted a change-oriented episode "to generate ideas on changes to current strategy in order to protect, grow and diversify the business", and a few months later undertook a stabilityoriented one "to consolidate strategy"; in the latter case, they quote the CEO as saying: "here's what we're actually going to do rather than here's what we might do" [emphases added].

Stability implies concentrating efforts on understanding the present needs of an organization, while change refers to interpreting the dynamic situational needs and adapting accordingly. Leaders often find themselves facing a choice between stability and change, and have to address issues such as: "How can I implement teams when the firm is in such turbulence?" (Lüsher and Lewis, 2008, 231). The notions of stability and change are often considered as fundamental organizational principles that strategists cannot escape dealing with. As Tsoukas and Chia argue, change "is not an exceptional or special activity individuals 
undertake, as one might be tempted to think from the perspective of stability" $(2002,577)$. Farjoun $(2010,205)$ notes that despite their conceptual distinctions, change and stability "are interdependent and potentially compatible - mutually enabling and a constituent of one another".

Thus, a key tension in strategy-making episodes relates to "change versus stability". Coordination/communication directs intraorganizational flow of information and knowledge, and affects the nature of strategic change wrought by strategy episodes and, ultimately, learning outcomes in terms of specifying whether existing capabilities are to be further utilized or new ones need to be developed (Hodgkinson et al., 2006; Johnson et al., 2010; MacIntosh et al., 2010).

While useful light has been shed on these three tensions, as previously noted, the SAP literature is curiously inattentive to cross-cultural influences. We therefore next turn our attention to cultural influences on the strategies that individuals may choose in dealing with the contradictions inherent in paradoxical tensions.

\section{Adopting Paradoxical Frames to Manage Tensions: East-West proclivities}

In considering the effect of culture on the extent of an individual's socialized proclivity to adopt paradoxical frames, our premise is that since culture shapes taken-for-granted norms - including of categorization processes (Keller and Chen, 2017b) - it will guide individuals' considerations about what is deemed "normal" in terms of episodic strategy-making which, of course, entail group decisions. Considering the same problem, one manager might accentuate integrating paradoxical elements and adopt paradoxical frames - mental representations embracing contradictions, whereas another manager would stress separating these elements and adopt a non-paradoxical frame (Keller et al., 2017). According to paradox research, people who embrace conflicting tensions tend to see them as opportunities, rather than threats, and feel comfortable with them, as opposed to those who try to resolve paradoxical tensions 
(Miron-Spektor, Ingram, Keller, Smith and Lewis, 2018). As recent studies suggest, these choices are influenced by culture: Easterners demonstrate a higher tendency to adopt paradoxical frames than Westerners due to different perceptions of contradictions embedded in their traditional cultures (Keller and Loewenstein, 2011; Keller and Lewis, 2016; Keller et al., 2017). Specifically, Keller et al. $(2017,541)$ empirically demonstrated a higher tendency of Chinese participants to embrace tensions compared to Americans:

Individuals with eastern cultural backgrounds tend to have paradox mindsets and so tend to use paradoxical frames. In contrast, individuals with western cultural backgrounds tend not to have paradox mindsets. They tend not to use paradoxical frames to encode conditions but instead tend to use an "either/or" perspective and categorize conditions using one category rather than both of two opposing categories.

The idea of paradox is consistent with Eastern indigenous philosophy that emphasizes relativity, holism and change (Keller and Lewis, 2016). As Li (2012) notes, thinking originating in ancient Chinese teachings accentuates the value of paradox, making it fundamentally different from Western systems of thought derived from Aristotle and Hegel. Eastern traditional thinking stresses the complementarity between opposing elements and their integration, and therefore, represents an alternative to Western thinking that emphasizes separation of conflicting elements ${ }^{2}(\mathrm{Li}, 2016)$. Other scholars concur, noting that Eastern philosophy views reality as being in a perpetual state of flux (Chia and Nayak, 2017), with paradox being the norm rather than the exception (Schad, 2017).

\footnotetext{
${ }^{2}$ In reality, as $\mathrm{Li}$ (2016) points out, the distinction is more complex and it may be more accurate to distinguish between absolute vs. partial separation/integration. In contrast to Aristotle's formal logic that implies a full separation of opposing elements and Hegel's dialectic logic that emphasizes a full integration of opposing element, Chinese philosophy is captured "in terms of a cognitive system of balancing opposite elements as partially conflicting and partially complementary... This unique epistemology balances the tradeoff and synergy between opposite elements as conflicting and complementary and, therefore, differs fundamentally from rational reductionism in Western epistemology as framed in Aristotle's formal logic and Hegel's dialectic" (2016, 50). For our purposes however, it suffices to make the simpler distinction between integration and separation. Future research could usefully explore more nuanced aspects of separation vs. integration.
} 
This is consistent with earlier studies showing Americans preferred noncompromising solutions to everyday-life contradictions, while Chinese participants demonstrated a higher tolerance for contradictions (Peng and Nisbett, 1999). Similarly, Spencer-Rodgers, Boucher, Mori, Wang and Peng (2009) reported that Chinese participants were more likely to endorse such statements as "When I hear two sides of an argument, I often agree with both", than EuroAmericans. These distinctive attitudes to contradictions can be explained by reliance on different thinking styles of Easterners and Westerners viz. a holistic and analytic thinking style, respectively (Peng and Nisbett, 1999; Nisbett, Peng, Choi and Norenzayan, 2001), that in turn are influenced by prevailing epistemologies. Specifically, Li $(2016,43)$ characterizes Western epistemology as "philosophy knowledge (as science-art separation for exploitation)", whereas Eastern epistemology is "philosophy of wisdom (as science-art integration for exploration)".

Western analytic thinking tends to view contradictory options as mutually exclusive (Smith and Lewis, 2011; Li, 2016), and typically relies on logical reasoning and involves splitting information into categories that are assessed independently (Peng and Nisbett, 1999). In dealing with conflicting tensions, analytic thinkers demonstrate an "either/or" logic and select the option that fits better with contingencies; pursuing opposing solutions simultaneously is viewed as wasteful (Chen, 2002; Nisbett et al., 2001). Its basic assumptions lead to a negative perception of ambiguity and perceiving paradox as abnormal state that should be avoided (Angeles, 1981; Li, 2016; Russel, 2007). Strategy practices are linked with each other in a cause-and-effect sequence: "Processes of environmental scanning lead to strategy formulation, leads to objective setting, leads to budget formulation, leads to performance feedback and adjustment and so on" (Redding, 1980, 143). This is also reflected in organizing events and tasks in a timeline: Westerners emphasize schedules, segmentation and accomplishing one 
thing in a predetermined slot (Redding, 1980). As such, adopting non-paradoxical frames to managing conflicting tensions will likely be typical of Western managers ${ }^{3}$.

Although often associated with dialectics (Peng and Nisbett, 1999), Eastern thinking is better understood as "either/and" Yin Yang balancing and duality (Li, 2016; Luo and Zheng, 2016). Li $(2016,53)$ emphasizes three distinctive features of Eastern duality thinking (vis-àvis Western dialectic logic): taking paradox as permanent yet relative (rather than temporarily necessary and to be resolved ultimately), viewing opposite elements "as partially conflicting and partially complementary" (in contrast to absolute negation of Western dialectic logic), and framing "the tradeoff and synergy between opposite elements as endogenous" (rather than exogenous). The concept of Yin Yang, which originated in Yi Jing (The Book of Changes), conveys the interaction and interdependence between pairs of opposing elements: hot and cold, good and bad, masculine and feminine, ugly and beautiful (Chen, 2008; Peng and Nisbett, 1999). Fang $(2012,34)$ summarizes the idea of Yin Yang in three principles: the co-existence, complementarity (and mutual reinforcement) and dynamic unity of opposites - that is, there is dynamic interdependence between polar contrasts (Chen, 2008; Eranova and Prashantham, 2016; Yang, 2006). Yin Yang philosophy's essence can be seen in the relation between becoming and being. As Mou (2008) points out, while most ancient Greek teachings prioritize being over becoming, and the Eastern Buddhist tradition emphasizes becoming over being, Yin Yang thinking suggests a third approach - "being-becoming complementarity" (Mou, 2008, 12). In contrast to Western thinking, the Eastern mind does not make a sharp distinction

\footnotetext{
${ }^{3}$ It would be wrong to claim that Western managers are incapable of paradoxical thinking; indeed much of the research published on paradoxical cognition (e.g. Andriopoulos and Lewis, 2010; Dameron and Torset, 2014; Smith, 2014) are undertaken in a Western setting. What we are arguing, however, is that the deep entrenchment of the paradox notion in Chinese culture makes Chinese managers significantly more likely to have positive affect towards paradox compared to Westerners. We view Western managers as tolerating but not enjoying the embracement of paradox. Hence, in an intense strategy conversation, we would expect Western managers to more readily default to a cognitive approach of greater comfort to them viz. adopting non-paradoxical frames whereas Chinese managers will more likely persist with paradoxical frames.
} 
between these two states and accepts their coexistence. $\operatorname{Li}(2016,50)$ explains how this feature of Eastern thinking differs from Western view of change and stability:

...the distinction between "becoming" and "being" is central to understanding this difference...while "being" refers to a fixed, certain, and complete status or form of an existence before acquiring its relationships with other entities, "becoming" refers to an interdependent and interactive process with other entities before and after any entity acquires its status or form.

Thus, culture influences the proclivity for managers to adopt paradoxical frames (Keller et al., 2017), stemming from different thinking styles - analytic and holistic (Peng and Nisbett, 1999). In Eastern settings the latter has been embedded in the social fabric through foundational concepts such as Yin Yang thinking which allows Easterners to adopt an "either/and" logic towards opposing elements allowing them to see contradictions as related and interdependent (Li, 1998, 2012, 2016). Although one has to be careful to avoid stereotyping, this represents a particularly intriguing difference between managers in the East and West (Keller and Loewenstein, 2011; Keller et al., 2017; Li, 2016). It is also worth recognizing that managers can be influenced by other cultures through sustained exposure and socialization. As Paine $(2010,104)$ notes, successful CEOs of European and American origin operating in China have to learn how "to play roles that Westerners often view as contradictory: They are strategic yet hands-on; disciplined yet entrepreneurial; process oriented yet sensitive to people; authoritative yet nurturing; firm yet flexible; and action driven yet circumspect".

Thus, a foundational idea in our model, summarized in Figure 1, relates to the influence of culture on the proclivity for adopting paradoxical frames.

Insert Figure 1 


\section{THEORY-BUILDING}

\section{Cultural Influence on Adopting Paradoxical Frames in Strategy Episodes}

Inclusion: Insiders vs. outsiders. How is the insider-outsider tension handled differentially within a given strategy episode in Eastern and Western contexts? In a Western setting where a traditional culture created preconditions for adopting non-paradoxical frames, the internal-external tension is dealt with by differentiating what happens within and outside episodes over the course of an episode series, which reflects the view that the goal of strategy episodes is generally to deliver actionable decisions over time. This, in turn, calls for decisiveness, highly valued in a Western context, which is easier to achieve among a core group of decision-makers (Healey et al., 2015; Johnson et al., 2010). Involving other stakeholders in order to obtain buy-in, could legitimate strategic decisions but may also undermine decisive strategizing by generating a diversity of viewpoints that have to be reconciled or, at a minimum, be given due consideration (MacIntosh et al., 2010). Strategy episodes therefore typically take the form of internal company events that occur separately from meetings with stakeholders who are not formally part of the company (Hodgkinson and Wright, 2002). Thus only internal core decision-makers usually take part in the episodes (Hodgkinson et al., 2006) while the wider set of stakeholders are consulted and kept informed through informal discussions in between internal strategy episodes (e.g. MacIntosh et al., 2010) or in separate formal episodes (Johnson et al, 2010). In sum, in the West, the inclusion tension tends to be resolved by engaging with insiders and outsiders separately (Healey et al., 2015; Johnson et al., 2010).

By contrast, in an Eastern setting, encouraged by a traditional culture to adopt paradoxical frames relevant outsiders may be included in the strategy episodes. Due to the holistic perception of reality (Keller et al., 2017; Li, 2016), the accent on relationships and the acknowledgement of the need to maintain these relationships in harmony nurtured by Yin Yang thinking means that external stakeholders are viewed as inseparable part of business activities 
of a company. Consistent with a paradoxical response to belonging-organizing tensions (Smith and Lewis, 2011), building and maintaining connections outside firm boundaries is viewed as highly important for (decisively) enacting present and future opportunities (Chen and Miller, 2011). This reflects a different approach to the internal-external tension in which strategymaking activities are not perceived as strictly intraorganizational processes, but rather as interdependent with other actors, sometimes even those in seemingly unrelated industries.

As a practical illustration of how the insider-outsider paradox could be embraced, in East Asia (especially China), external stakeholders may include local government officials (Fernandez and Underwood, 2009; Guo, Huy and Xiao, 2017), as reflected in this observation by Jack Ma, Alibaba's founder: “Always try to stay in love with the government, but don't marry them" (quoted in Leng, 2014). Thus business leaders must gain government support without letting their plans get stymied. Also, the Chinese government is often involved in improving the public image of a firm through recognizing outstanding leaders, which was part of the strategic success for Haier Group and Huawei Technologies (Li and Zhou, 2005). It is therefore not uncommon for Chinese organizations to invite local government officials to strategy meetings (Fernandez and Underwood, 2009; Paine, 2010) ${ }^{4}$.

While this specific behavior (aligning strategy with state priorities) may reflect not only informal institutional norms that underpin paradoxical thinking but also formal institutional realities such as regulatory uncertainty in a context like China's, our emphasis is on the broader cultural approach that it depicts, viz. the blurred distinction between internal and external stakeholders within strategy episodes. From a Western perspective, such behavior could seem rather odd, even unethical, invoking concerns about nepotism and corruption. However, although this possibility cannot be ruled out, it is plausible that a genuine exchange of ideas

\footnotetext{
${ }^{4}$ For example, we learned from a field interview that the CEO of a large Chinese private business group, had government officials from the local municipal education department attend his company's strategy meetings about the long term strategy of the group's proposed foray into international schooling.
} 
and perspectives does occur between diverse stakeholders who are culturally predisposed to seeing themselves as inextricably linked (Chen and Miller, 2011). We therefore posit:

P1: (a) A group of managers whose cultural context supports a proclivity for adopting paradoxical frames will integrate rather than separate insiders and outsiders in a strategy episode. (b) By contrast, a group of managers whose cultural context does not support a proclivity for adopting paradoxical frames will separate rather than integrate insiders and outsiders in a strategy episode.

Formality: Formal vs. informal. What is the default approach to the formal-informal tension in the West? Descriptions of strategy episodes (e.g. Bourque and Johnson, 2008; Johnson et al., 2010; MacIntosh et al., 2010) suggest that in a Western setting, due to a low proclivity for adopting paradoxical frames different parts of a given episode involve informal socializing and formal business activity, associated with distinctive objectives (social and organizational, respectively). Organizational objectives likely reflect the Western perspective that a free and frank exchange of views between members is generally desirable, thus resulting in an emphasis on debating strategic options (Jarzabkowski and Seidl, 2008). Yet it is also recognized that vigorous debate may cause friction that turns into destructive hostility (Hodgkinson and Wright, 2002; Johnson et al., 2010).

The strategy episode literature, therefore, notes the significance of bonding, i.e. cultivating positive affect amongst participants, in order to enable debate that is robust but not hostile (Healey et al., 2015; MacIntosh et al., 2010). Research suggests that social bonds are built more readily through less formal socializing than formal deliberation (Johnson et al., 2010). However, these are typically dealt with in turn, not together. For example, Bourque and Johnson (2008) describe how on the evening prior to a strategy workshop conducted by a Western corporation, participants gathered together for a meal to break the ice or renew bonds in an informal setting, with little expectation that actual decision-making would take place during this time. The following morning, participants got down to business. Of course in the West also managers may dine together and discuss strategic issues. However, in general, there 
is a far greater emphasis on creating distinct boundaries between social and business aspects of a strategy episode (Johnson et al., 2010). A compartmentalized approach to addressing the formal-informal tension, which may recur over time, can thus be discerned.

By contrast, in an Eastern setting, due to a high proclivity for adopting paradoxical frames there is likely to be much greater fluidity between the social and business facets of an episode. According to the principle of Yin Yang, "contradictory elements coexist in all things at all times" (Ma-Kellams, Spencer-Rodgers and Peng, 2011, 16). This means that social and business activities also naturally coexist in strategy-making events. It was found, for example, that Chinese entrepreneurs, both local and returnee, adopt formal and informal business processes simultaneously (Lin, Lu, Li and Liu, 2015). Chinese CEOs consider socializing with groups of employees and taking an interest in their personal lives as part of strategy work, whereas for Western top managers, "time spent on soft issues like these is time lost on hard ones such as achieving performance targets and improving productivity" (Paine, 2010, 106). Thus, while common efforts are directed at searching for strategy-related outcomes, participants simultaneously pursue the goal of building harmonious relationships. Easterners' preference for consensus over open confrontation stimulates interaction between the social and business aspects of group engagement (Chen, 2008).

To illustrate in practical terms, formal strategy discussions may take place during informal social engagement (or, conversely, informal strategy conversations may be embedded within formal social meals). Indeed, it is not uncommon for strategy episodes to take the form of dinners among top managers and select external participants. This goes beyond socializing to represent a key forum for strategy development (Fernandez and Underwood, 2009). In practical terms, this is facilitated by the availability of separate rooms within regular mainstream restaurants, which afford a level of privacy to top management teams and their external guests. Another notable practice that could be alien to most Western managers is the 
consumption of (often copious amounts of) alcohol - which does not necessarily inhibit business discussions. Rather, discussing business and strengthening relationships over food and drink may be seen as inseparable (Paine, 2010).

Thus, in an Eastern setting where paradoxical thinking predominates, the boundaries are far more blurred. To a Western eye, some of these events may seem rather unconventional as strategy episodes given the lack of formal tools, flipcharts and other associated paraphernalia (Hodgkinson et al., 2006). However, non-trivial levels of time, effort and expenditure go into intense meal-time engagement, and there is often palpable change or confirmation of strategy in their aftermath. Thus, in contrast to Healey et al.'s (2015) pithy title, “off to plan or out to lunch?" [emphasis added], which arguably reflects a Western approach without paradoxical frames, Eastern managers may well have a meal and plan simultaneously. Thus:

P2: (a) A group of managers whose cultural context supports a proclivity for adopting paradoxical frames will integrate rather than separate formal and informal elements in a strategy episode. (b) By contrast, a group of managers whose cultural context does not support a proclivity for adopting paradoxical frames will separate rather than integrate formal and informal elements in a strategy episode.

Coordination/communication: Change vs. stability. In a Western setting, due to its higher cultural propensity to adopt non-paradoxical frames, the change-stability tension is oftentimes addressed by conducting separate episodes focusing on either, during the course of a series of episodes. The default Western position is captured succinctly by Johnson et al (2010) who argue that without clarity about whether an episode is concerned with change or stability (i.e. continuity) the event is likely to fail. Therefore, Western managers will typically assign different purposes (discussing change by formulating strategy versus reinforcing stability via implementing strategy) to different episodes, as it would be more logical to focus effort on each, separately. This approach, of course, is cognizant of there being some level of both emergence of strategy and deliberate planning. Yet the role of strategic planning in coordinating and communicating organizational strategy is typically manifested in episodic 
strategizing by addressing issues of strategic change and stability separately (Jarzabkowski and Seidl, 2008; Johnson et al., 2010).

By contrast, in an Eastern setting, due to its higher cultural propensity to adopt paradoxical frames change and stability are viewed as deeply intertwined interdependencies (Chen, 2002; Li, 1998) and so are likely to be simultaneously addressed in a given episode. This is consistent with Paine's $(2010,104-5)$ observation that in China, top managers "understand the market but work with the state". The paradox-based decision-making of Eastern managers likely leads them to consider existing and future activities within the same episode. Their holistic perception allows Eastern managers to view change-related initiatives as a way to resolve current (stability-related) issues, and strategies for existing activities as helping to plan new moves (change).

To illustrate, discussions in a strategy episode may not clearly distinguish between challenges for current stability, such as ensuring efficiency of current operations, and challenges for future growth, such as diversifying or differentiating future offerings. The beingbecoming relation of Yin Yang thinking enables Easterners to see these two states as interdependent and so, for instance, conversations about current staffing needs and future succession planning may merge into a single discussion. This may lead to decisions such as that of Zhang Yong, a founder of hot pot restaurant chain Hai Di Lao, to hire teenagers capable of becoming store managers by the time they reach the age of 21 , as they are valued for what they can grow into in future rather than what they are at present moment (Hout and Michael, 2014). In the Eastern mind, there is no clear separation between existent and emergent, as a current state ("being") is a changed state of the past ("becoming"), and the future state is "becoming" of the present "being" (Mou, 2008). Therefore, there is no need to focus attention either on a current situation or future plans at separate timeslots, as these two states transform one into another in the being-becoming interplay (Li, 2016; Mou, 2008). 
This view of change manifests in attempts to achieve a balance between a situational momentum and purposeful intentions, stimulated by searching for harmony between immediate and future concerns (Jing and Van de Ven, 2014). To Western observers, Eastern managers can, therefore, appear to be lurching incoherently from one strategy to another in a semi-permanent liminoid (i.e. between-and-betwixt) state (Johnson et al., 2010). However, it has been argued that being "consistently inconsistent" is the hallmark of paradoxical decisionmaking (Smith, 2014, 1592). As such, it would be common for Eastern managers to discuss stability and change in relation to the other at the same time, rather than to organize different episodes to tackle each. Therefore, we suggest:

P3: (a) A group of managers whose cultural context supports a proclivity for adopting paradoxical frames will integrate rather than separate change- and stability-related elements in a strategy episode. (b) By contrast, a group of managers whose cultural context does not support a proclivity for adopting paradoxical frames will separate rather than integrate change- and stability-related elements in a strategy episode.

\section{Managing Tensions in Strategy-Making Episodes over Time}

While the foregoing three propositions highlight tensions in a given strategy episode, paradox theory also highlights the importance of a dynamic perspective in viewing how tensions are managed over time. This is helpful to our conceptualization since the literature notes that strategy episodes often occur as a sequence or series (Jarzabkowski and Seidl, 2008; Johnson et al., 2010). The final part of our model therefore reflects strategy-making as an ongoing process involving the design and conduct strategy episodes from time to time.

Synthesizing the preceding three propositions, we note a mechanism that some managers - especially those lacking a proclivity for adopting paradoxical frames - may use to deal with the various tensions we have discussed: inter-episode plurality. That is, as seen from qualitative studies of strategy episodes in the West (e.g. Bourque and Johnson, 2008; Hodgkinson and Wright, 2002; Jarzabkowski and Seidl, 2008; Johnson et al., 2010; MacIntosh et al., 2010), these managers are likely to have separate episodes that engage internal and 
external stakeholders, adopt formal and informal formats and consider matters of stability and change. The temporal distinctness of such episodes may vary: in some cases they may be weeks apart, in others there may be mini-episodes nested in the same, say, three-day episode (e.g. Bourque and Johnson, 2008). This pattern is evident from an account of Western firms'strategy making process which describes how top managers "created separate time to learn about the exploitative and exploratory strategies, using different meetings or parts of meetings...[these firms] all held off site meetings focused specifically on their exploratory business models" (Smith, Binns and Tushman, 2010, 455; emphasis added).

Such inter-episode plurality contrasts with the intra-episode plurality likely to be seen when managers who naturally adopt paradoxical frames are involved. Intra-episode plurality implies an inbuilt flexibility into episodes whereby it is deemed appropriate to include a "mish mash" of attributes with apparently contradictory elements coexisting in a given episode, as noted in our arguments for P1a, P2a and P3a. That is, the same episode will tend to incorporate formal and informal aspects, internal and external actors, and a focus on stability and change - with the distinctions blurring into each other. By repeating this approach of integrating opposing elements in the same episode over time, managers become habituated to this plurality on an ongoing basis, as opposed to less paradoxically inclined managers who are more attuned to situation-dependent behaviors i.e. there is, for instance, a time and place to be formal, which is distinct from a time and place to be informal.

The practice of dealing with these contradictory issues in parallel means that it is not uncommon for strategic and tactical issues to consistently feature across strategy episodes. While this may also reflect, in part, other cultural facets such as high power distance between senior managers (decision-makers) and more junior managers (implementers), the key point is that, over time, there is likely to be less perceived differentiation across episodes due to the holistic (versus analytical) style of thinking underpinning these group activities. An implication 
is that to observers who are socialized in Western practices of inter-episode plurality, strategy episodes could appear to be more disorganized and less coherent in terms of their agenda ${ }^{5}$. These contrasting approaches to tensions are summarized in Table 1, which includes illustrations of inter-episode plurality from SAP studies in the West (including some referred to in the Background section) and intra-episode plurality based on anecdotal observations in the East referred to in our preceding discussions of P1, P2 and P3.

Insert Table 1

Thus, when viewed from a dynamic perspective, it is not as if managers rooted in different cultural contexts vary in their competence in dealing with tensions in strategy episodes per se. Rather, they manage them differently, within and across strategy episodes. This difference is likely to be an important, and hitherto overlooked, cross-cultural difference between managers in the East and West, as well as individuals who are extensively socialized in the business etiquette and dealings of one or the other context. In sum, we posit:

P4: Strategy episode series involving a group of managers from a cultural context that supports the adoption of paradoxical frames will be characterized by intra-episode plurality whereas those involving a group of managers from a cultural context that does not support the adoption of paradoxical frames will be characterized by inter-episode plurality.

\section{Intra- vs Inter-episode plurality and different approaches to strategy-making}

What are the implications of separating tensions in strategy episodes (inter-episode plurality) versus integrating them (intra-episode plurality) in terms of broad approaches to strategy-making? The Western approach of inter-episode plurality supports a strategy

\footnotetext{
${ }^{5}$ Arguably, our arguments can also be couched in terms of Feldman and Pentland's (2003) distinction between ostensive aspects (abstract patterns) and performative aspects (specific actions) of organizational routines: in a Western setting there is likely to be more variation in ostensive aspects of episodes over time (inter-episode plurality) whereas in an Eastern setting there will likely be more variation in performative aspects within a given episode (intra-episode plurality) - and conversely less performative variation in a given episode (West) and less ostensive variation across episodes (East).
} 
development process which is ostensibly planned but allows for emergence (Grant, 2003; MacIntosh and MacLean, 1999). A strategic planning calendar may guide the scheduling and focus of strategy episodes, but the opportunity that managers have to design different episodes with different foci (e.g. a stability-oriented workshop following a change-oriented one) means that there is room for emergent ideas to take root and, perhaps, be validated by the planning process (Hodgkinson et al., 2006; Johnson et al., 2010). Thus a series of varied episodes provides the venue for emergence within a planning framework.

By contrast, the Eastern approach of intra-episode plurality is driven by a more emergent process - with no a priori calendric process - which could give rise to rapidly developed plans (Huang, 2009). The greater involvement of other stakeholders in a given episode could lead to creating and refining concrete proposals that are shared with and bought into by the parties concerned. But it also means that in an Eastern setting, a top management team may not deem it necessary for planning and execution to follow in a linear sequence. Williamson (2016, 205) observed in Chinese companies that there often was "extreme horizontal flexibility in marshalling and recombining resources" to execute strategies that were "often swiftly decided upon, after which immediate action was taken".

Such an approach to strategy-making, in which new strategic actions may be initiated before an ongoing initiative is completed, represents a marked departure from Western proclivities, as illustrated by the following reflections of an American who worked for several years as an Alibaba executive in China:

"I was taught to approach a decision by gathering all relevant data and submitting them to rigorous frameworks and analysis before making a long term plan. But at Alibaba I often found that this style was at odds with the approach of my colleagues... Over time I developed instincts for anticipating and smoothly adjusting to the company's frequent strategic changes and simply going with the flow" (Erisman, 2016, 233).

Thus, we have a nuanced perspective of two different ways at getting at planned emergence which is consistent with the being-becoming distinction (Mou, 2008; Tsoukas and 
Chia, 2002) highlighted earlier. The Western approach - which is rooted in the being worldview - takes goal-oriented planning as the starting point but allows for emergence. Grant $(2003,491)$ refers to this as "planned emergence", an approach in which "strategic planning systems provide a mechanism for coordinating decentralized strategy formulation”. By contrast, the Eastern approach - which is rooted in the becoming worldview - favors the emergence of strategy from the "intrinsic flux of human action" (Tsoukas and Chia, 2002, 567), and tilts the process towards a modicum of planning to concretize the ideas that take root. We suggest that this could be considered to be "emergent planning", an approach in which continuous emergent ideas and actions provide the basis for intermittent planned activities that may be sudden in formulation. Thus we posit:

P5: Strategy episode series characterized by inter-episode plurality will tend to support a "planned emergence" approach to strategy-making (one that is ostensibly rooted in a planning process but accommodates the emergence of strategy) whereas those characterized by intraepisode plurality will tend to support an "emergent planning" approach to strategy-making (driven by an emergent approach but incorporates planning, often done rapidly).

\section{DISCUSSION}

In this paper we seek to redress the paucity of a cross-cultural perspective in SAP research on strategy episodes by conceptualizing how managers deal with paradoxical tensions in strategy-making episodes, and highlighting potential ways in which the design and conduct of these episodes might differ as a result of cultural influences. We conceptualize differing approaches (separating versus integrating) to managing tensions in relation to inclusion, formality and coordination/communication in distinct cultural contexts, notably the East and West, which lead to intra- and inter-episode plurality, respectively, over time. Below we discuss the paper's contributions, limitations, and implications for future research and managerial practice. 


\section{Contributions}

The core insight from our conceptual work in this paper relates to how the cultural context can shape distinct approaches to dealing with paradoxical tensions in strategy episodes. We expect these differences to be particularly strong between Western settings (which is the predominant context for SAP research) and Eastern contexts such as China, whose significance has risen greatly in recent times. This insight has useful implications for both the SAP and paradox literatures.

Contributions to the SAP literature. We contribute to SAP research by highlighting plausible distinctions between paradox-embracing (Eastern) and paradox-resisting (Western) contexts in terms of how tensions in the design and conduct of strategy episodes are addressed. Thus there may be significant differences in how Eastern and Western managers do strategy work. A greater understanding of how managers exposed to Eastern and Western influence strategize differently contributes to constructing a complete picture of strategy work. Our insight demonstrates that the SAP domain can illuminate our collective understanding of EastWest differences beyond extant well-worn clichés (e.g. communication styles or individualism-versus-collectivism). In so doing we respond to Whittington's (2006) call for developing explicit links between extraorganizational influences and strategy practices by highlighting the role of cultural-cognitive norms embedded within informal institutions. Our conceptualization offers an opportunity to look at strategy episodes as culturally embedded events (Vaara and Lamberg, 2016), and our specific focus on East-West differences lays a foundation for future research that can respond to Vaara and Whittington's (2012) call for exploring contexts like China.

We also shed light on how distinct strategy episode practices over time may support distinct strategy-making approaches. A key theoretical insight is that adopting paradoxical frames is likely to result in intra-episode plurality, whereas non-paradoxical frames will tend 
to engender inter-episode plurality over time, in terms of the choices made between opposing poles in paradoxical tensions, as observed in thick descriptions of strategy workshop series in the West (Jarzabkowski and Seidl, 2008; Johnson et al., 2010; MacIntosh et al., 2010). In turn, this distinction is likely to support different approaches to strategy-making: planned emergence versus emergent planning. In the West, managers are utilized predominantly as part of planned strategy and feature less in emergent strategy - since one has to plan and set up the episodes. In the East, in contrast, managers may combine the planning of the strategy episode with an explicit recognition of the emergent processes that they allow for. Hence, they plan a context for emergence to happen. Whereas the Western approach of planned emergence (Grant, 2003) could lead to coherent strategy development (albeit justified in hindsight, in some cases), the Eastern approach is likely to aid speed of strategy execution (Williamson, 2016).

Contributions to the paradox literature. Although our primary audience for this article is the SAP research stream, we believe that our ideas also hold relevance for the paradox literature (e.g. Smith and Lewis, 2011; Miron-Spektor et al., 2018). Compared to the SAP literature, some work on paradox has been more attuned to East-West cross-cultural differences (e.g. Keller et al., 2017; Li, 2016) - and indeed, constitutes an important building block for our conceptualization. Yet even this stream of work, we argue, could benefit from our specific focus on strategy practices. To illustrate, Keller and Chen (2017a) recently noted how crosscultural differences in the use of paradoxical frames may influence the categories of issues (e.g. cooperation and competition) that are emphasized by top managers in strategy development, but stop short of examining practice-related implications in the tradition of SAP. Our ideas such as intra- versus inter-episode plurality - and the broader associated distinction between emergent planning and planned emergence - could lend greater specificity to such work in further teasing out cross-cultural differences in strategy development. Our model thus offers a basis for digging further into the intersection between strategy practice, paradox and culture. 
More generally, our work also provides paradox scholars with potentially useful insight into hitherto under-researched tensions. For instance, an oft-mentioned broad paradox that organizations face relates to the competing demands for control and flexibility (Lewis, 2000), yet there is more research on other tensions that such exploration versus exploitation, cooperation versus competition, or social versus commercial objectives in social entrepreneurship (Schad et al., 2016). Arguably, the three tensions we address relating to participation, performativity and purpose of strategy episodes reflect more specific manifestations of the broader control-flexibility tension. Thus, choices favoring insiders (participants), formality (performativity) and stability (purpose) are likely engender control whereas their corresponding poles of choosing outsiders, informality and change likely yield greater flexibility. Furthermore, there may be scope to understand the nature (type) of these tensions such as, for instance, how the participation tension relates to belongingness (Smith and Lewis, 2011). Thus, by studying actors' responses to tensions involved in the design and conduct of practices such as strategy episode, paradox researchers may be able to synthesize a greater understanding of the control-flexibility tension.

\section{Limitations and Future Research}

The ideas in this paper could inform a research program in SAP focusing on crosscultural influences. Although in the interests of parsimony and clarity we focus somewhat narrowly on strategy episodes, the basic ideas around responses to paradoxical tensions could have much wider application in SAP research. That said, we are aware that while our preliminary conceptualization of East-West differences in strategy episodes offers a useful start, it is inattentive to several issues - and these could form the basis for future research.

First, we acknowledge that in talking about the East, our focus has primarily been on China. This leaves out vast swathes of Eastern contexts, such as South Asia, which deserve greater attention in their own right. Future research could usefully look into other contexts that 
are likely to be different from the West, but also distinct from China. A notable example is India. Although possessing different cultural roots from the West (with some similarities to those of China), its very different colonial past and political outlook has led to greater cultural plurality whereby managerial elites in India are likely to be more Westernized in their strategy practices compared to their Chinese counterparts. Other cross-national differences are also ripe for consideration, such as the institutional environment. Non-Eastern settings such as Russia and Brazil would provide a useful basis to draw different foci in comparisons from our focus in this paper.

Second, in focusing on cultural differences and approaches to dealing with tensions, our emphasis is on cultural-cognitive norms that relate to informal institutions; yet, formal institutions may also influence the praxis of strategic planning. Future research could usefully examine the impact of formal rules and regulations (or of their absence), for instance, as well as how formal and informal institutions interact to influence episodic strategizing. Informal institutions could relate to the role of biculturals, migrants and returnees that we ignore for simplicity of exposition we offer stark characterizations of the East and West. Yet such networks might bridge different institutional contexts leading to hybrid strategy practices that combine influences from different contexts. Future research could examine this prospect. Also, little is known about strategy episodes when both Western and Eastern managers are involved, and this represents a potentially fruitful research area for future research. That is, research could consider interactions between cultures within the same strategy episode, especially when conducted in the context of a multicultural team.

Third, while we have emphasized the complementarity between paradox theory and Yin Yang balancing (Keller and Lewis, 2016), future research could highlight the epistemological distinctiveness of the latter ( $\mathrm{Li}, 2016)$. Applying Yin Yang balancing will allow scholars to further explore how conflicting elements are balanced in an asymmetrical mix and what 
contextual conditions determine dominance of one pole of the tension over another. We believe that strategy episodes offer an intriguing context for exploring this further, and hope that our set of testable propositions will stimulate further research at the intersection of SAP and paradox (Lê and Bednarek, 2017).

As such, we open up a hitherto underexplored empirical setting for SAP research to branch out into, as it matures and grows in global influence. A notable deficiency in this stream of literature is a lack of consideration of cross-cultural differences across managers, reflecting the largely Western bias of the empirical settings used in this research. However with the rise of emerging markets such as China, it seems shortsighted and incomplete to restrict empirical enquiry to the West. A more broad-based understanding of managerial behavior is warranted, to advance research theoretically as well as to enhance the practical relevance of our work as management researchers. Our insights into the plausible impact of differences in thinking style with respect to context, which is shaped by the overall cultural context, provides a useful basis to dig more into cross-cultural differences, in particular between East and West, in SAP research.

\section{Practitioner implications}

Our ideas, if empirically supported, have useful managerial implications. First, managers must recognize the tensions they face in carrying out episodes and be adept in managing issues like the inclusion of participants, level of formality and their role within the strategic planning process. This may well make a considerable difference to their strategizing efficacy. Second, managers in the West would do well to reflect upon how they might (selectively) adopt paradoxical frames (Prashantham, Eranova and Couper, 2018), and consider what they might learn from an Eastern approach, perhaps in certain episodes. Finally, Eastern and Western managers engaging in joint strategizing require sensitivity to differences in their collaborators' proclivities in terms of how they undertake strategy work. Strategy practices 
originating in the West without suitable adaptation may not readily diffuse to the modernizing economies of the East. Also, our conceptual work here provides a foundation to not only consider how Chinese companies such as Alibaba differ in the content of their strategy from, say, Amazon or eBay but, importantly, in the way that people do strategy. For a company like Alibaba, which launched a global leadership academy that hires several non-Chinese MBAs from top business schools around the world, understanding the cross-cultural nuances of strategy practices could be vital in ensuring that such programs provide their new hires with sufficient orientation to cope with these differences. Otherwise, it seems likely that the attrition rate of such programs will be high. As such, Eastern and Western managers need to take into account differences in their approaches to strategizing.

\section{Conclusion}

In a global economy, there is a continued need for scholars and practitioners to refine their understanding of differences in managerial behaviors across cultural contexts. An important area warranting greater attention pertains to East-West differences in strategy episodes since this activity constitutes an important and effortful (but not always successful) endeavor in organizations. The idea that Eastern and Western managers may do strategy work differently due to extraorganizational influences represents a valuable insight which highlights strategy episodes as a valuable context for a fruitful line of enquiry that further connects the burgeoning literatures on paradox and strategy practice. 


\section{REFERENCES}

Andriopoulos, C., Lewis M.W., 2010. Managing innovation paradoxes: Ambidexterity lessons from leading product design companies. Long Range Planning 43 (1), 104-122.

Angeles, P.A., 1981. A dictionary of philosophy. London: Harper \& Row.

Barkema, H.G., Chen, X-P, George, G., Luo, Y., Tsui, A.S. 2015. West meets East: New concepts and theories. Academy of Management Journal 58 (2), 460-479.

Bourque, N., Johnson, G. 2008. Strategy Workshops and "Away-Days" as Ritual. In G.P. Hodgkinson, W.H. Starbuck (Eds). The Oxford Handbook of Organizational Decision Making. New York: Oxford University Press.

Burgelman, R.A., Floyd, S.W., Laamanen, T., Mantere, S., Vaara, E., Whittington, R. 2018. Strategy processes and practices: Dialogues and intersections. Strategic Management Journal.

Chen, M.J., 2002. Transcending paradox: The Chinese "middle way" perspective. Asia Pacific Journal of Management 19 (2-3), 179-199.

Chen, M.J., 2008. Reconceptualizing the competition-cooperation relationship: A transparadox perspective. Journal of Management Inquiry 17 (4), 288-304.

Chen, M.J., Miller, D., 2011. The relational perspective as a business mindset: Managerial implications for East and West. Academy of Management Perspectives 25 (3), 6-18.

Chia, R. \& Nayak, A. (2017). Circumventing the logic and limits of representation: Otherness in East-West approaches to paradox. In W.K. Smith, M.W. Lewis, P. Jarzabkowski \& A. Langley (Eds.), The Oxford Handbook of Organizational Paradox (p. 125-140), Oxford: Oxford University Press.

Dameron, S., Torset, C., 2014. The discursive construction of strategists' subjectivities: Towards a paradox lens on strategy. Journal of Management Studies 51 (2), 291-319.

Dutton, J.E., Dukerich, J.M., Harquail, C.V., 1994. Organizational images and member identification. Administrative science quarterly 39 (2), 239-263.

Eranova, M., Prashantham, S., 2016. Decision making and paradox: Why study China?, European Management Journal, 34, 193-201.

Eppler, M.J., Platts, K.W., 2009. Visual strategizing: the systematic use of visualization in the strategic-planning process. Long Range Planning, 42 (1), 42-74.

Erisman, P. 2016. Alibaba's World: How a remarkable Chinese company is changing the face of global business, Pan Macmillan, London.

Fang, T., 2012. Yin Yang: A new perspective on culture. Management and Organization Review 8 (1), 25-50.

Farjoun, M., 2010. Beyond dualism: Stability and change as a duality. Academy of Management Review 35 (2), 202-225.

Feldman, M. S., Pentland, B. T. 2003. Reconceptualizing organizational routines as a source of flexibility and change. Administrative Science Quarterly, 48(1), 94-118.

Fernandez, J.A., Underwood, L., 2009. China Entrepreneur. London: Wiley.

Ginzel, L., Kramer, R., Sutton, B. 1993. Organizational impression management as a reciprocal influence process: The neglected role of the organizational audience. In L.L. 
Cummings, B.M. Staw (Eds.), Research in organizational behaviour (15), 227- 266. Greenwich, CT: JAI Press.

Grant, R., 2003. Strategic planning in a turbulent environment: Evidence from the oil majors. Strategic Management Journal 24 (6), 491-517.

Guo, Y., Huy, Q.N., Xiao, Z. 2017. How middle managers manage the political environment to achieve market goals: Insights from China's state-owned enterprises. Strategic Management Journal 38 (3): 676-696.

Hautz, J., Seidl, D., Whittington, R. 2017. Open strategy: Dimensions, dilemmas, dynamics. Long Range Planning 50: 298-309.

Healey, M.P., Hodgkinson, G.P., Whittington, R., Johnson, G., 2015. Off to plan or out to lunch? Relationships between design characteristics and outcomes of strategy workshops. British Journal of Management 26 (3), 507-528

Hendry, J., Seidl, D., 2003. The structure and significance of strategic episodes: Social systems theory and the routine practices of strategic change. Journal of Management Studies 40 (1), 175-196.

Hodgkinson, G.P., Wright, G. 2002. Confronting strategic inertia in a top management team: learning from failure. Organization Studies 23 (6), 949-977.

Hodgkinson, G.P., Whittington, R., Johnson, G., Schwarz, M., 2006. The role of strategy workshops in strategy development processes: Formality, communication, co-ordination and inclusion. Long Range Planning 39 (5), 479-496.

Hout, T., Michael, D. 2014. A Chinese approach to management. Harvard Business Review, 92 (9), 103-107.

Huang, X. 2009. Strategic decision making in Chinese SMEs. Chinese Management Studies 3(2), 87-101.

Jarzabkowski, P., Lê, J., 2017. We have to do this and that? You must be joking: Constructing and responding to paradox through humor. Organization Studies 38 (3-4), 433 462 .

Jarzabkowski, P., Lê, J., Van de Ven, A.H. 2013. Responding to competing strategic demands: How organizing, belonging, and performing paradoxes coevolve. Strategic Organization, 11 (3), 245-280.

Jarzabkowski, P., Seidl, D., 2008. The role of meetings in the social practice of strategy. Organization Studies 29 (11), 1391-1426.

Jing, R., Van de Ven, A.H., 2014. A Yin-Yang Model of Organizational Change: The Case of Chengdu Bus Group. Management and Organization Review 10 (1), 29-54.

Johnson, G., Prashantham, S., Floyd, S.W., Bourque N. 2010. The ritualization of strategy workshops. Organization Studies 31 (12), 1589-1618.

Keller, J., Chen, E.W. 2017a. Culture, paradoxical frames, and behavioral strategy. In Das, T.K. (Ed.) Culture and Behavioral Strategy (p. 101-124). Charlotte, NC: Information Age.

Keller, J., Chen, E.W. 2017b. A road map of the paradoxical mind: Expanding cognitive theories on organizational paradox. In W.K. Smith, M.W. Lewis, P. Jarzabkowski \& A. Langley (Eds.), The Oxford Handbook of Organizational Paradox (p. 66-86), Oxford: Oxford University Press. 
Keller, J., Lewis, M.W., 2016. Moving towards a geocentric, polycultural theory of organizational paradox. Cross Cultural \& Strategic Management, 23 (4), 551-557.

Keller, J., Loewenstein, J., 2011. The cultural category of cooperation: A cultural consensus model analysis for China and the United States. Organization Science 22 (2), 299-319.

Keller, J., Loewenstein, J., Yan, J., 2017. Culture, conditions and paradoxical frames. Organization Studies 38 (3-4), 539-560.Kryger, A. 2018. Iterative prototyping of strategy implementation workshop design. Journal of Strategy and Management, 11 (2), 166183.

Lê, J., Bednarek, R. 2017. Paradox in everyday practice. 2017. In P. Jarzabkowski, A. Langley, M. Lewis, \& W. Smith (Eds) Oxford Handbook of Organizational Paradox: Approaches to plurality, tensions, and contradictions. Oxford University Press: Oxford.

Leng, S. 2014. ' 'Be in Love With Them, but Don't Marry Them'. Foreign Policy: 31 October. Available at http://foreignpolicy.com/2014/10/31/be-in-love-with-them-but-dontmarry-them/

Lewis, M.W., 2000. Exploring paradox: Toward a more comprehensive guide. Academy of Management Review 25 (4), 760-776.

Li, M., Zhou, H. 2005. Knowing the business environment: The use of non-market-based strategies in Chinese local firms. Ivey Business Journal, 12, 1-6.

Li, P.P., 1998. Toward a geocentric framework of organizational form: A holistic, dynamic and paradoxical approach. Organization Studies 19 (5), 829-861.

Li, P.P., 2012. Toward an integrative framework of indigenous research: The geocentric implications of Yin-Yang balance. Asia Pacific Journal of Management, 29 (4), 849-872.

Li, P.P. 2016. Global implications of the indigenous epistemological system from the east: How to apply Yin-Yang balancing to paradox management. Cross Cultural \& Strategic Management 23 (1), 42-77.

Lin, D., Lu, J., Li, P.P., Liu, X., 2015. Balancing formality and informality in business exchanges as a duality: A comparative case study of returnee and local entrepreneurs in China. Management and Organization Review 11 (2), 315-342.

Luo, Y.D., Zheng, Q.Q., 2016, Competing in complex cross-cultural world: Philosophical insights from Yin-Yang, Cross Cultural \& Strategic Management, 23 (2), 386-392.

Lüscher L., Lewis, M., 2008. Organizational change and managerial sensemaking: Working through paradox. Academy of Management Journal 51 (2), 221-240.

Ma-Kellams, C., Spencer-Rodgers, J., Peng, K., 2011. I am against us? Unpacking cultural differences in ingroup favoritism via dialecticism. Personality and Social Psychology Bulletin, 37 (1), 15-27.

MacIntosh, R., MacLean, D. 1999. Conditioned emergence: A dissipative structures approach to transformation. Strategic Management Journal 20 (4), 297-316.

MacIntosh, R., MacLean, D., Seidl, D. 2010. Unpacking the effectivity paradox of strategy workshops: Do strategy workshops produce strategic change? In Golsorkhi, D., Rouleau, L., Seidl, D., Vaara, E. (Eds.) Cambridge Handbook of Strategy as Practice (pp. 8-20).

Cambridge: Cambridge University Press. 
Miron-Spektor, E., Ingram, A., Keller, J., Smith, W.K., Lewis, M.W., 2018.

Microfoundations of organizational paradox: The problem is how we think about the problem. Academy of Management Journal 61 (1), 26-45.

Mou, B. 2008. History of Chinese philosophy. New York: Routledge.

Nisbett, R.E., Peng, K., Choi, I., Norenzayan, A. 2001. Culture and systems of thought: Holistic versus analytic cognition. Psychological Review 108 (2), 291-310.

Paine, L.S. 2010. The China rules. Harvard Business Review 88, 103-108

Peng, K., Nisbett, R.E. 1999. Culture, dialectics, and reasoning about contradiction. American Psychologists 54 (9), 741-754.

Pettigrew, A., Woodman, R., Cameron, K. 2001. Studying organizational change and development: Challenges for future research. Academy of Management Journal 44 (4), 697 713.

Prashantham, S., Eranova, E., Couper, C. 2018. Globalization, entrepreneurship and paradox thinking. Asia Pacific Journal of Management 35(1), 1-9.

Rasche, A., Seidl, D.A., 2018. Luhmannian perspective on strategy: Strategy as paradox and meta-communication. Critical Perspectives on Accounting, in press.

Redding, S.G., 1980. Cognition as an aspect of culture and its relation to management processes: An exploratory view of the Chinese case. Journal of Management Studies 17 (2), $127-148$

Russell, B., 2007. My philosophical development. Nottingham: Spokesman.

Schad, J. (2017). Ad fontes: Philosophical foundations of paradox research. In W.K. Smith, M.W. Lewis, P. Jarzabkowski \& A. Langley (Eds.), The Oxford Handbook of Organizational Paradox (p. 27-47), Oxford: Oxford University Press.

Schad, J., Lewis, M.W., Raisch, S., Smith, W.K. 2016. Paradox research in management science: Looking back to move forward. The Academy of Management Annals 10 (1), 5-64.

Sewchurran, K., Dekker, J., McDonogh, J. 2018. Experiences of embedding long-term thinking in an environment of short-termism and sub-par business performance: investing in intangibles for sustainable growth. Journal of Business Ethics, in press.

Smith, W.K., 2014. Dynamic decision making: A model of senior leaders managing strategic paradoxes. Academy of Management Journal 57 (6), 1592-1623.

Smith, W.K., Binns, A., Tushman, M.L. 2010. Complex business models: Managing strategic paradoxes simultaneously. Long Range Planning 43 (2-3), 448-461.

Smith, W.K., Lewis, M.W., 2011. Toward a theory of paradox: A dynamic equilibrium model of organizing. Academy of Management Review 36 (2), 381-403.

Spencer-Rodgers, J., Boucher, H.C., Mori, S.C., Wang, L., Peng, K., 2009. The dialectical self-concept: Contradiction, change, and holism in East Asian cultures. Personality and Social Psychology Bulletin 35 (1), 29-44.

Tsoukas, H., Chia, R. 2002. On organisational becoming: Rethinking organizational change. Organizational Science 13, 567-582.

Vaara, E., Lamberg, J.A., 2016. Taking historical embeddedness seriously: Three historical approaches to advance strategy process and practice research. Academy of Management Review 41 (4), 633-657. 
Vaara, E., Whittington, R., 2012. Strategy-as-practice: taking social practices seriously. The Academy of Management Annals 6 (1), 285-336.

Williamson, P.J. 2016. Building and leveraging dynamic capabilities: Insights from accelerated innovation in China. Global Strategy Journal 6(3): 197-210.

Whittington, R. 1993. What is strategy - and does it matter? London: International Thomson Business Press.

Whittington, R. 2006. Completing the practice turn in strategy research. Organization Studies 27 (5), 613-634.

Whittington, R. 2007. Strategy practice and strategy process: Family differences and the sociological eye. Organization Studies 28 (10), 1575-1586.

Whittington, R., Cailluet, L. 2008. The crafts of strategy: Special issue introduction by the guest editors. Long Range Planning 41(3), 241-247.

Whittington, R., Yakis-Douglas, B., Ahn, K., Cailluet, L. 2017. Strategic planners in more turbulent times: The changing job characteristics of strategy professionals, 1960-2003. Long Range Planning, 50, 108-119.

Wolf, C., Floyd, S.W., 2017. Strategic planning research: Toward a theory-driven agenda. Journal of Management 43 (6), 1754-1788.

Yang, C.F., 2006. The Chinese conception of the Self: Towards a person-making perspective. In: Kim, U., Yang, K.S., Hwang, K.K. (Eds.) Indigenous and cultural psychology:

Understanding people in context, (pp. 327-356). New York: Springer. 
Table 1. Managing paradoxical tensions in strategy episodes: Intra- versus inter-episode plurality

\begin{tabular}{|c|c|c|c|}
\hline $\begin{array}{c}\text { Strategy episode } \\
\text { characteristic }\end{array}$ & $\begin{array}{c}\text { Specific } \\
\text { tension }\end{array}$ & $\begin{array}{c}\text { Illustration of inter- } \\
\text { episode plurality }\end{array}$ & $\begin{array}{c}\text { Illustration of intra- } \\
\text { episode plurality } \\
\text { (embracing tensions) }\end{array}$ \\
\hline $\begin{array}{c}\text { Inclusion } \\
\text { (Participation } \\
\text { tension) }\end{array}$ & $\begin{array}{c}\text { Insiders } \\
\text { vs. } \\
\text { outsiders }\end{array}$ & $\begin{array}{c}\text { Exclusively involving } \\
\text { direct reports of the CEO } \\
\text { in certain episodes versus } \\
\text { including middle } \\
\text { managers or external } \\
\text { partners in separate ones } \\
\text { (Hodgkinson and Wright, } \\
\text { 2002). }\end{array}$ & $\begin{array}{c}\text { Involving internal and } \\
\text { external stakeholders } \\
\text { consistently in the same } \\
\text { episode; this may even } \\
\text { include local government } \\
\text { officials' views on } \\
\text { strategic decisions being } \\
\text { considered. }\end{array}$ \\
$\begin{array}{c}\text { Formality } \\
\text { (Performativity } \\
\text { tension) }\end{array}$ & $\begin{array}{c}\text { Formal vs. } \\
\text { informal }\end{array}$ & $\begin{array}{c}\text { Formal strategy } \\
\text { discussions in a meeting } \\
\text { room distinguished from } \\
\text { the informal setting of } \\
\text { the bar (Bourque and } \\
\text { Johnson, 2008). }\end{array}$ & $\begin{array}{c}\text { Combining formal and } \\
\text { informal dimensions of } \\
\text { an episode; e.g. having } \\
\text { strategic discussions } \\
\text { within the more informal } \\
\text { setting of a meal }\end{array}$ \\
$\begin{array}{c}\text { Coordination/ } \\
\text { Communication } \\
\text { (Purpose } \\
\text { tension) }\end{array}$ & Change \\
vs. & stability & $\begin{array}{c}\text { Episodes focusing on } \\
\text { new strategy formulation } \\
\text { (generating ideas for } \\
\text { business diversification) } \\
\text { as distinct from ones } \\
\text { concerned with existing } \\
\text { strategy implementation } \\
\text { (Johnson et al., 2010). }\end{array}$ & $\begin{array}{c}\text { Merging discussions on } \\
\text { short- and long-term } \\
\text { issues or planning and } \\
\text { implementation, in the } \\
\text { same episode, which may } \\
\text { even generate a plan of } \\
\text { action that addresses both } \\
\text { of these poles. }\end{array}$ \\
\hline
\end{tabular}

Note: While the illustrations of inter-episode plurality from the West are drawn from thick descriptions of strategy workshops in prior studies, the illustrations of intra-episode plurality in the East primarily reply on our anecdotal observations, notably in China, due to the paucity thus far of published research on strategy episodes in such settings. 
Figure 1. East-West differences in addressing tensions in episodic strategizing

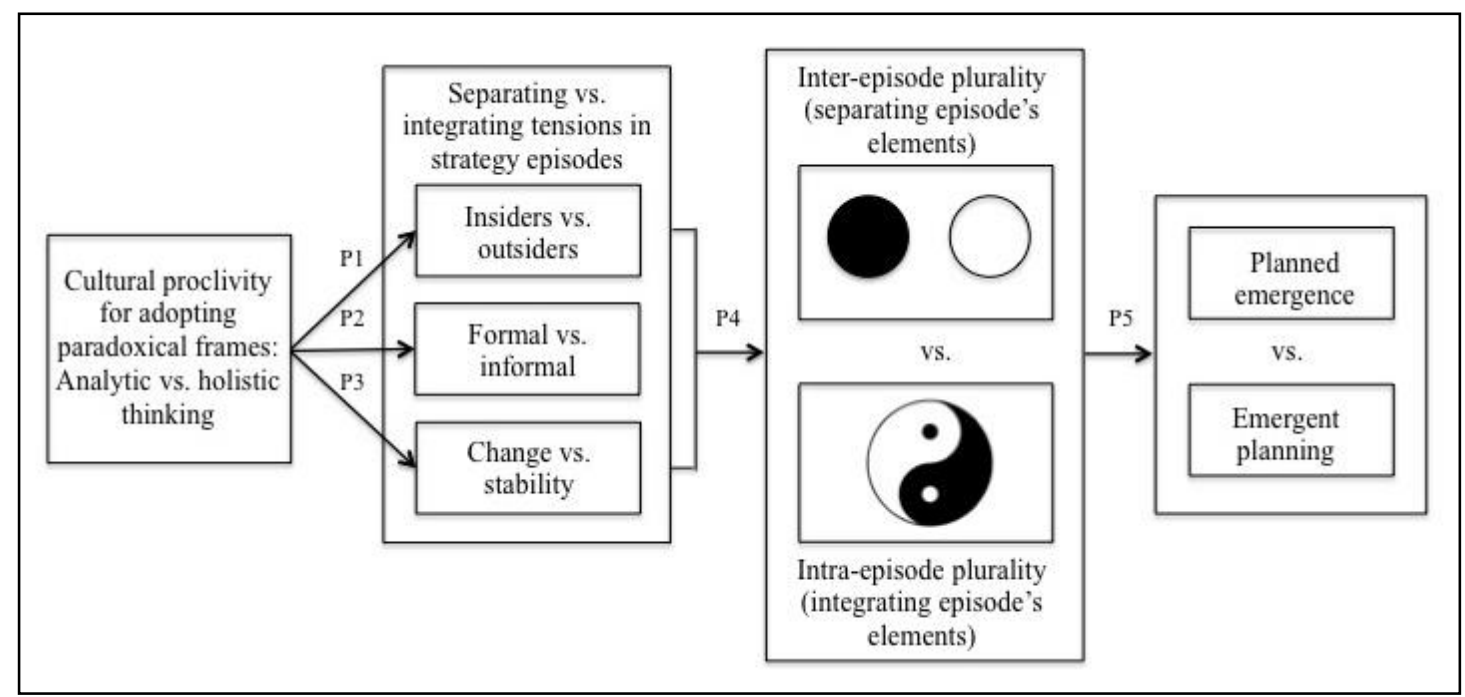

